\title{
Survival of patients with advanced NSCLC treated with first-generation EGFR-TKIs at a cancer hospital in Thailand, 2011-2016.
}

\author{
Sitthi Sukauichai ${ }^{1 *}$, Chokaew Tovanabutra ${ }^{2}$, Sirentra Wanglikitkul ${ }^{2}$, Kittisak Chomprasert ${ }^{2}$ \\ ${ }^{1}$ Chemotherapy Unit, Chonburi Cancer Hospital, Chonburi, Thailand. \\ ${ }^{2}$ Radiotherapy Unit, Chonburi Cancer Hospital, Chonburi, Thailand.
}

\begin{abstract}
Objective: The present study was to determine survival of the patients with advanced Non-Small Cell Lung Cancer (NSCLC) treated with Epidermal Growth Factor Receptor-Tyrosine Kinase Inhibitors (EGFR-TKIs) at Chonburi Cancer Hospital (CCH).

Material and Methods: The study was conducted retrospectively by review of medical records of stage IIIB-IV NSCLC patients treated with first-generation EGFR-TKIs at CCH from January, 2011December, 2016.

Results: The present study enrolled 50 patients with median follow up time 16.78 months. The median age of patients was 58.5 . There were female (46\%), non-smoking $(62 \%)$ and adenocarcinoma $(90 \%)$. The sources of EGFR-TKI were a reimbursement system (32\%), purchase for themselves $(52 \%)$ and free drug samples (14\%). Eastern Cooperative Oncologic Group (ECOG) performance status was 0-1 (54\%), 2-4 (28\%) and Non-Available (NA) (18\%). The median Overall Survival (OS) of all patients were 17.18 months. The OS of the patients receiving EGFR-TKIs as first-line or maintenance $(n=18)$, second-line $(n=18)$ and third-line or more $(n=14)$ were $15.86(95 \% C I, 10.26-21.46), 10.87(95 \% C I$, 0.00-28.29) and $20.23(95 \% \mathrm{CI}, 6.26-34.21)(\mathrm{p}=0.392)$ months, respectively. Regarding EGFR status, the OS of patients with EGFR sensitizing-mutation (22\%), wild-type (12\%) and unknown (66\%) were 30.75 (95\% CI,13.76-47.74), 7.91 (95\% CI, 0.00-20.45) and 13.99 (95\%CI, 9.17-18.82) ( months, respectively. Multivariate analysis indicated that smoking $(p=0.006)$, ECOG performance status 2-4 and NA $(p<0.001)$, receiving EGFR-TKIs by payment $(p=0.040)$ and compassionate use $(p<0.001)$ were the unfavorable prognostic factors for the OS.

Conclusion: In spite of the fact that most of the patients started an EGFR-TKI before their EGFR status was confirmed and often received it as a second-line or more. The OS of patients harbouring EGFR sensitizing-mutation in the present study was comparable to those of other pivotal studies.
\end{abstract}

Keywords: Advanced non-small cell, Lung cancer, Overall survival, First-generation EGFR-TKIs

Accepted on 09 August 2018

\section{Introduction}

Lung carcinoma was the most common and leading cause of death from cancer worldwide in 2012 [1]. In Thailand at the same time, it was the second cause of death from malignancy.

Treatment paradigm in advanced stage Non-Small Cell Lung Carcinoma (NSCLC) has been shifted from a group of chemotherapy [2] fitting all to individualized targeted-drugs [3-9], emerging immunotherapy [10] and most recently some combinations of them [11]. Nonetheless, personalized therapy remains the pillar of treatment in patients with specific driver mutations including Anaplastic Lymphoma Kinase (ALK) gene rearrangements, ROS proto-oncogene 1 (ROS1) gene rearrangements, B-Raf (BRAF) proto-oncogene point mutation, and most commonly Epidermal Growth Factor Receptor (EGFR) gene mutations[12-13].
Apparently, the clinical efficacy of Epidermal Growth Factor Receptor-Tyrosine Kinase Inhibitors (EGFR-TKIs) in patients harbouring an EGFR mutation was proved by a lot of pivotal trials [3-9,14-16] showed in Table 1. At the beginning, a few prestigious studies [3-4] revealed that clinical features of patients (eg. non-smokers and adenocarcinoma) were not good enough to indentify the proper of them for front-line therapy with EGFR-TKIs. In other words, only patients with EGFR sensitizing mutation gained benefit from EGFR-TKIs, while those with EGFR wild type had detrimental effects in terms of Overall Response Rate (ORR) and progression free survival when compared with chemotherapy. Later studies [5-9] choosing EGFR mutated patients hammered such both of the superiorities of EGFR-TKIs over chemotherapies, and could provide median overall survivals to $19-34$ months, however no 
Citation: Sukauichai S,Tovanabutra C, Wanglikitkul S, et al. Survival of patients with advanced NSCLC treated with first-generation EGFRTKIs at a cancer hospital in Thailand, 2011-2016. J Med Oncl Ther 2018;3(2):23-31.

difference of survival time was found between both arms due to high crossover rates.

Table 1. Selected phase III studies of first-generation EGFR-TKIs in advanced NSCLC;* statistically significant difference. Abbreviation: Cb: Carboplatin; CI: Confidence Interval; Cis: cisplatin; CoR: Crossover Rate; Doc: Docetaxel; EGFR: Epidermal Growth Factor Receptor; EGFRTKIs: Epidermal Growth Factor Receptor-Tyrosine Kinase Inhibitors; Gem: Gemcitabine; HR: Hazard Ratio; mo: month; mt: EGFR mutation; N: Number of patients; NSCLC: Non-Small Cell Lung Cancer; ORR: Overall Response Rate; OS: Overall Survival; Pac: Paclitaxel; PFS: Progression Free Survival; vs: Versus.

\begin{tabular}{|c|c|c|c|c|c|c|c|}
\hline Study & Patient features & $\mathrm{N}$ & Treatment & ORR (\%) & $\begin{array}{l}\mathrm{PFS}(\mathrm{mo}) \\
\mathrm{HR}(95 \% \mathrm{Cl})\end{array}$ & $\mathrm{OS}(\mathrm{mo})$ & $\operatorname{CoR}(\%)$ \\
\hline \multirow[b]{3}{*}{ IPASS } & \multirow{6}{*}{$\begin{array}{l}\text { Clinical Selection\# } \\
\text { with subset EGFR } \\
\text { mutation analysis }\end{array}$} & & \multirow{3}{*}{$\begin{array}{l}\text { Gefitinib } \\
\text { vs } \\
\mathrm{Pac} / \mathrm{Cb}\end{array}$} & \multirow{3}{*}{$\begin{array}{l}\text { All } 43.0 \text { vs } 32.2^{*} \\
\mathrm{mt}+71.2 \text { vs } 41.3^{*} \\
\mathrm{mt}-1.1 \text { vs } 23.5^{*}\end{array}$} & 5.7 vs 5.8 & 18.8 vs 17.4 & \multirow{3}{*}{$\begin{array}{l}39 \\
40\end{array}$} \\
\hline & & & & & $0.48(0.36 \text { to } 0.64)^{*}$ & 21.6 vs 21.9 & \\
\hline & & 608 & & & $2.85\left(2.05\right.$ to $3.98^{*}$ & 11.2 vs 12.7 & \\
\hline \multirow[b]{3}{*}{ First-SIGNAL } & & \multirow{2}{*}{159} & \multirow{3}{*}{$\begin{array}{l}\text { Gefitinib } \\
\text { vs } \\
\text { Gem/Cis }\end{array}$} & \multirow{3}{*}{$\begin{array}{l}\text { All } 55.4 \text { vs } 46.0 \\
\text { mt+ } 84.6 \text { vs } 25.9^{*} \\
m t-25.9 \text { vs } 51.9\end{array}$} & 5.8 vs 6.4 & 22.3 vs 22.9 & \multirow{3}{*}{$\begin{array}{l}65 \\
75\end{array}$} \\
\hline & & & & & 8.0 vs 6.3 & 27.2 vs 25.6 & \\
\hline & & 150 & & & 2.1 vs 6.4 & 18.4 vs 21.9 & \\
\hline \multirow[b]{2}{*}{ NEJ002 } & \multirow{10}{*}{$\begin{array}{l}\text { EGFR mutation } \\
\text { positive }\end{array}$} & 114 & Gefitinib & $73.7^{*}$ & $10.8^{*}$ & 30.5 & 46 \\
\hline & & 114 & $\mathrm{Pac} / \mathrm{Cb}$ & 30.7 & 5.4 & 23.6 & 93 \\
\hline & & 86 & Gefitinib & $62.1^{*}$ & $9.2^{*}$ & $34 . .8$ & 20 \\
\hline WJTOG 3405 & & 86 & Doc/Cis & 32.1 & 6.3 & 37.3 & 59 \\
\hline \multirow[b]{2}{*}{ EURTAC } & & 86 & Erlotinib & $64.0^{*}$ & $9.7^{*}$ & 19.3 & 32 \\
\hline & & 87 & Cis-based & 18 & 5.2 & 19.5 & 76 \\
\hline \multirow{4}{*}{ OPTIMAL } & & 82 & Erlotinib & $82.9^{*}$ & $13.1^{*}$ & 22.8 & 59 \\
\hline & & 72 & Gem/Cb & 36.1 & 4.6 & 27.2 & 69 \\
\hline & & 110 & Erlotinib & $62.7^{*}$ & $11.0^{*}$ & 26.3 & 59 \\
\hline & & 107 & Gem/Cis & 33.6 & 5.5 & 25.5 & 85 \\
\hline
\end{tabular}

Several real world studies [17-22] about first-generation EGFR-TKIs from different counties were reported (Table 2). In Thailand, although there are many clinical reports about the treatment and efficacy with EGFR-TKIs [23-26], very few studies were about a first-generation EGFR-TKI treatment. The primary aim of this study was to find survival and also to show a treatment regimen in advanced NSCLC patients treated using first-generation EGFR-TKIs in a real clinical setting at Chonburi Cancer Hospital $(\mathrm{CCH})$, a referral cancer center in the East of Thailand.

\section{Material and Methods}

The researcher retrospectively reviewed medical records of patients with NSCLC stage IIIB -IV according to International Union Against Cancer (seventh edition) [27], confirmed by histology including an imaging and treated with EGFR- TKIs in CCH during January, 2011 to December, 2016. All patients were followed up until December 31, 2017. A status of the patient at the cut-off time was taken from the medical record and registration information, Ministry of Interior, Thailand. This study was approved by Ethics committee of $\mathrm{CCH}$.

Table 2. Some real-life studies regarding overall survival in EGFR mutated advanced NSCLC; Abbreviation: EGFR: Epidermal Growth
Factor Receptor; EGFR-TKIs: Epidermal Growth Factor ReceptorTyrosine Kinase Inhibitors; mo: month; N: Number of patients; NSCLC: Non-Small Cell Lung Cancer; OS: Overall Survival.

\begin{tabular}{|l|l|l|l|l|}
\hline Country & Study year & N & $\begin{array}{l}\text { First line } \\
\text { EGFR-TKls } \\
(\%)\end{array}$ & $\begin{array}{l}\text { Median OS } \\
(\mathrm{mo})\end{array}$ \\
\hline US & $2002-2009$ & 137 & 67.9 & 30.9 \\
\hline Japan & $2008-2012$ & 1656 & 63.9 & 29.7 \\
\hline Spain & $2010-2011$ & 181 & 81.5 & 20.1 \\
\hline French & $2011-2013$ & 361 & 80.3 & 24.6 \\
\hline China & $2011-2013$ & 226 & 100 & 26.9 \\
\hline Indonesia & $2013-2016$ & 40 & 100 & 10 \\
\hline
\end{tabular}

An Overall Survival time (OS) was calculated from the starting date of systemic therapy to the date of death or the date when the patient was last known to be alive. Time to Treatment Failure (TTF) was calculated from the date of starting EGFRTKIs treatment to the date of tumor progression or death or changing/stop of the treatment for some reasons. Tumor responses were assessed using Response Evaluation Criteria in Solid Tumors (RECIST) criteria [28] based on radiologic 
report (CT scan or plain-film) and physical examination. Processing time was calculated from the date of a physician' request for molecular testing to the date of receiving tissue at a laboratory, and Turn-Around Time (TAT) was calculated from the date of receiving tissue to the date of result report from a laboratory; both were reported in official day(s).

\section{Statistical analysis}

OS was calculated using the method of Kaplan and Meier. Twenty variables were included in the analyses to identify prognostic factors of OS. Comparisons of cumulative survival were obtained by univariate analyses using the log-rank test and multivariate analyses were performed using Cox proportional hazard regression. A p-value $<0.05$ in univariate analysis and multivariate analysis were considered statistical significant difference. Statistical Package for the Social Sciences (SPSS) version 16.0 was used in this study.

\section{Results}

Sixty-four medical records of patients were reviewed. Among them, fourteen were excluded; fifty patients fulfilled our criteria to include in this study (Figure 1).

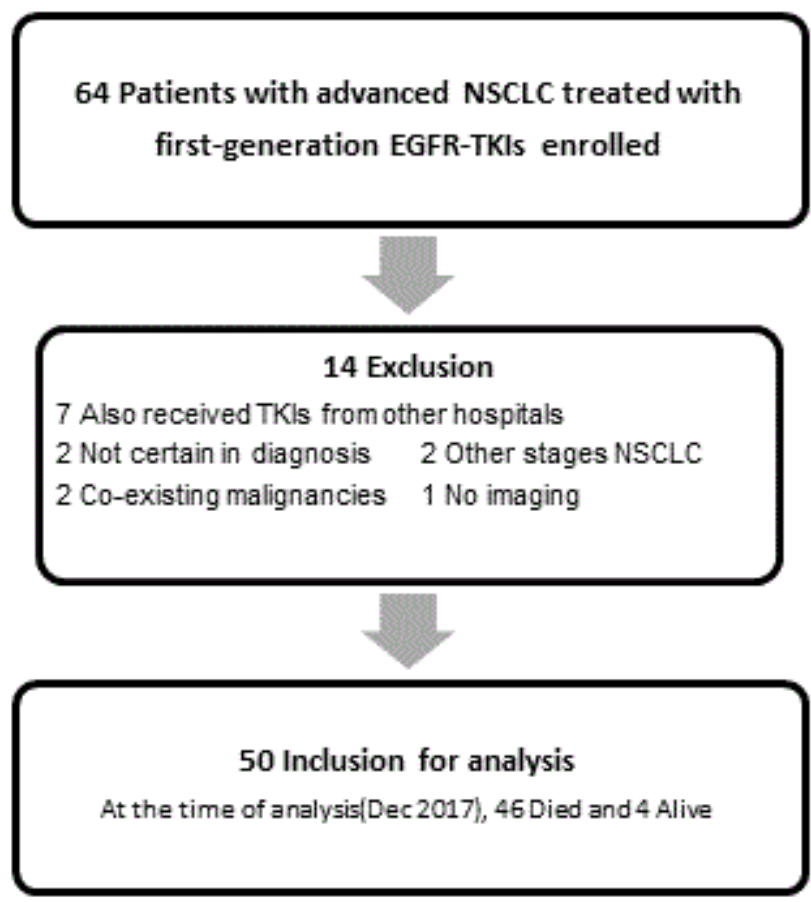

Figure 1. Enrollment, exclusion from the study and included patients

\section{Patients and baseline characteristics}

Patient characteristics were shown in Table 3. Fifty-two percent of the patients got access to an EGFR-TKI by purchasing for themselves, whereas one-third (32\%) of them received a TKI by a reimbursement system and the other (14\%) received it as free drug sample or compassionate use. In terms of health fund group, there were Universal Coverage Scheme $(n=21$ : payment 17, compassionate use 4), Social Security Scheme $(n=12$ : reimbursement 3 , payment 6 , compassionate use 2, combined way 1) and Government Servant and
Enterprise Organization ( $\mathrm{n}=17$ : reimbursement 13 , payment 3, compassionate use 1). The median regimen of all systemic therapies was three.

Regarding EGFR mutation status, eleven patients (22\%) harboured EGFR sensitizing- mutation, nine of whom were exon 19 mutations, one of whom was exon 21 mutation, and the last one of whom was combined exon 19+21 mutation. While thirty-three patients $(66 \%)$ remained EGFR unknown and the others (12\%) had EGFR wild-type, respectively.

Table 3. Patient characteristics; ${ }^{*}$ median age (min-max), years, ${ }^{* *}$ one patient received by a combined way, ${ }^{* * *}$ ECOG performance status at the time of the first systemic therapy " others; 2 no otherwise specified, 2 poorly differentiated carcinoma, llarge cell carcinoma. Abbreviation: ECOG-PS, Eastern Cooperative Oncology Groupperformance status; EGFR, epidermal growth factor receptor; $N$, number; TKI, tyrosine kinase inhibitor

\begin{tabular}{|c|c|c|}
\hline $\mathrm{N}=50$ & Factor & $N(\%)$ \\
\hline \multirow{2}{*}{ Sex } & Male & $27(54.0)$ \\
\hline & Female & $23(46.0)$ \\
\hline Age $^{*}$ & $58.5(31-85)$ & - \\
\hline \multirow{2}{*}{ Smoking } & Never & $31(62.0)$ \\
\hline & Current/former & $19(38.0)$ \\
\hline \multirow{3}{*}{ TKI access ${ }^{* *}$} & Reimbursement & $16(32.0)$ \\
\hline & Payment & $26(52.0)$ \\
\hline & Compassionate use & $7(14.0)$ \\
\hline \multirow{3}{*}{ ECOG- PS ${ }^{\star \star *}$} & $0-1$ & $27(54.0)$ \\
\hline & $2-4$ & $14(28.0)$ \\
\hline & NA & $9(18.0)$ \\
\hline \multirow{2}{*}{ Stage } & IIIB & $2(4.0)$ \\
\hline & IV & $48(96.0)$ \\
\hline \multirow{2}{*}{ Histopathology } & Adenocarcinoma & $45(90.0)$ \\
\hline & Others\# & $5(10.0)$ \\
\hline \multirow{2}{*}{ Tissue } & Pathology & $43(86.0)$ \\
\hline & Cytology & $7(14.0)$ \\
\hline \multirow{3}{*}{ EGFR mutation status } & Sensitizing & $11(22.0)$ \\
\hline & Wild-type & $6(12.0)$ \\
\hline & Unknown & $33(66.0)$ \\
\hline \multirow{2}{*}{ Chemotherapy } & Yes & $43(86.0)$ \\
\hline & No & $7(14.0)$ \\
\hline \multirow{2}{*}{ Radiotherapy } & Yes & $27(54.0)$ \\
\hline & No & $23(46.0)$ \\
\hline
\end{tabular}

Median processing time and TAT of EGFR mutation testing were 9.5 (95\% CI, 1.00-42.00) and 5 (95\% CI, 1.00-13.00) official days. 
Citation: Sukauichai S,Tovanabutra C, Wanglikitkul S, et al. Survival of patients with advanced NSCLC treated with first-generation EGFRTKIs at a cancer hospital in Thailand, 2011-2016. J Med Oncl Ther 2018;3(2):23-31.

\section{EGFR-TKIs Treatment and Efficacy}

Eighteen patients (36\%) received a Tyrosine Kinase Inhibitor (TKI) as first-line (1L) $(\mathrm{n}=16)$ or maintenance $(\mathrm{MN})$ therapy $(\mathrm{n}=2)$. Eighteen patients $(36 \%)$ and fourteen patients $(28 \%)$ received it as second-line $(2 \mathrm{~L})$ and third-line $(3 \mathrm{~L})$ or more therapy, respectively. Gefitinib and erlotinib were provided in thirty-five $(70 \%)$ and fifteen $(30 \%)$ patients, respectively. Response stratified by line of EGFR treatment and EGFR status was shown in Table 4.

Table 4. EGFR-TKIs treatment and response; *Loss to follow up (1), Died (1), \# Loss to follow up, \$ No measurable lesion (leptomeningeal metastasis). Abbreviation: EGFR: Epidermal Growth Factor Receptor; EGFR-TKI: Epidermal Growth Factor Receptor-Tyrosine Kinase Inhibitor; $n$ : number of patients; NA: Not Available; PD. Progression of Disease; PR: Partial Response; SD: Stable Disease

\begin{tabular}{|c|c|c|c|c|c|c|}
\hline \multirow{2}{*}{$\begin{array}{l}\text { Line of EGFR- } \\
\text { TKI }\end{array}$} & \multirow{2}{*}{$\begin{array}{l}\text { EGFR } \\
\text { mutation } \\
\text { status }\end{array}$} & \multicolumn{4}{|c|}{ Response to EGFR-TKI(n) } & \multirow[t]{2}{*}{ Total $(n)$} \\
\hline & & PR & SD & PD & NA & \\
\hline \multirow{3}{*}{$\begin{array}{l}\text { First-line/ } \\
\text { maintenance } \\
(n=16+2)\end{array}$} & Sensitizing & 3 & 1 & 0 & 0 & 4 \\
\hline & Wild-type & 0 & 2 & 0 & 0 & 2 \\
\hline & Unknown & 4 & 4 & 2 & $2^{*}$ & 12 \\
\hline \multirow{3}{*}{$\begin{array}{l}\text { Second-line } \\
(n=18)\end{array}$} & Sensitizing & 1 & 3 & 0 & 0 & 4 \\
\hline & Wild-type & 0 & 0 & 1 & $1^{\#}$ & 2 \\
\hline & Unknown & 5 & 2 & 4 & $1^{\#}$ & 12 \\
\hline \multirow{3}{*}{$\begin{array}{l}\text { Third-line } \\
\text { more } \\
(n=14)\end{array}$} & Sensitizing & 2 & 1 & 0 & 0 & 3 \\
\hline & Wild-type & 0 & 0 & 1 & $1^{\$}$ & 2 \\
\hline & Unknown & 1 & 1 & 5 & $2^{*}$ & 9 \\
\hline \multicolumn{2}{|l|}{ Total $(n)$} & 16 & 14 & 13 & 7 & 50 \\
\hline
\end{tabular}

Interestingly, six patients with EGFR wild-type received an EGFR-TKI, three of whom received it during waiting for EGFR testing results and were stopped after the result showed EGFR wild-type, while the other three received it continuously until disease progression or death.

As for EGFR unknown, the reasons for not to test EGFR status before starting a TKI therapy were (a) treatment by physicians' or patients' decision $(\mathrm{n}=14)$, (b) no requirement by reimbursement system $(n=6)$, (c) empiric therapy in poor ECOG performance status/critically ill patients $(n=6)$, (d) inadequate tissue specimen or diagnostic cytology $(n=4)$, and combined reasons $(\mathrm{c})$ and $(\mathrm{d})(\mathrm{n}=3)$.

Of all patients, median TTF was 4.00 (95\% CI, 0.42-21.25) months. Median TTF of patients treated with $1 \mathrm{~L}$ or MN , 2L and $3 \mathrm{~L}$ or more were 4.41 (95\% CI,0.23-28.78), 4.64 (95\% CI, 0.42-26.74) and 2.29 (95\% CI, 0.46-16.75) months, respectively. Median TTF of EGFR sensitive mutation, wild type, and EGFR unknown were 8.41 (95\% CI, 3.18-16.75), 4.30 (95\% CI, 0.46-15.77) and 1.77 (95\% CI, 0.36-27.35) months, respectively. The causes of treatment failure (in the first period of treatment time) were disease progression ( $n=33)$, dead $(n=6)$, loss follow-up $(n=6)$, physician's decision $(n=3)$, a side effect $(\mathrm{n}=1)$ and financial problem $(\mathrm{n}=1)$.

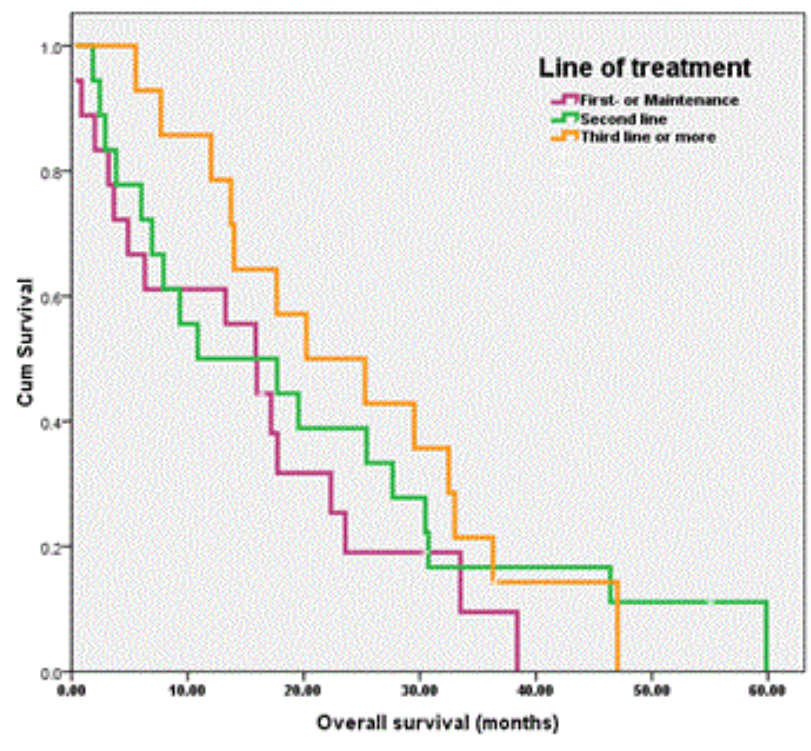

Figure 2. Overall survival based on line of TKI therapy

Moreover, nine patients received EGFR-TKIs more than one period of treatment time (re-challenge or changing strategy), five of whom received TKIs up to three periods. Four patients also received a second generation EGFR-TKI (such as afatinib) as a changing regimen. The median TTF of nine patients received re-challenge or changing TKIs regimen progressively declined from 5.71 (95\% CI, 1.37-16.78) to 3.58 (95\% CI, $0.36-13.17)$ and to $1.74(95 \% \mathrm{CI}, 1.44-2.85)$ months in the first-, the second- and the third-period of treatment time, respectively. In the first period of treatment, responses showed partial response $(n=6)$, stable disease $(n=2)$ and progression of disease $(n=1)$.

\section{Survival}

Forty-six patients died prior to the cut point time - December 31, 2017, with median follow up time of 16.78 months. Four patients were alive. Three of them were receiving different systemic therapies which were docetaxel, gefitinib and osimertinib, while the other one received best supportive care.

The median OS of all patients was 17.18 months and those of the patients receiving EGFR-TKIs as $1 \mathrm{~L}$ or $\mathrm{MN}, 2 \mathrm{~L}$ and $3 \mathrm{~L}$ or more were $15.86(95 \% \mathrm{CI}, 10.26-21.46), 10.87$ (95\% CI, $0.00-28.29)$ and 20.23 (95\% CI, 6.26-34.21) months, respectively. As for EGFR status, the OS of patients with EGFR sensitizing-mutation, wild-type and unknown was 30.75 (95\% CI, 13.76-47.74), 7.91 (95\% CI, 0.00-20.45) and 13.99 (95\% CI, 9.17-18.82) months, respectively. The OS of patients according to line of TKIs treatments and EGFR status were shown in Figures 2 and 3, respectively.

Among the group of patient with unknown EGFR status, the median OS classified by the reasons of starting TKI treatment was 30.48 (95\% CI, 0.00-61.79) months for patients in reimbursement system $(\mathrm{n}=6), 17.74(95 \% \mathrm{CI}, 9.73-25.75)$ months for patients treated by clinical judgments $(n=14$ : female 10/14, adenocarcinoma 12/14, non-smoking 13/14), 3.84 (95\% CI, 0.00-12.04) months for patients with poor 
ECOG performance status $(\mathrm{n}=6)$ and $3.64 \quad(95 \% \quad \mathrm{CI}$, 0.00-18.52) months for patients with cytology-proved lung cancer $(\mathrm{n}=4)$.

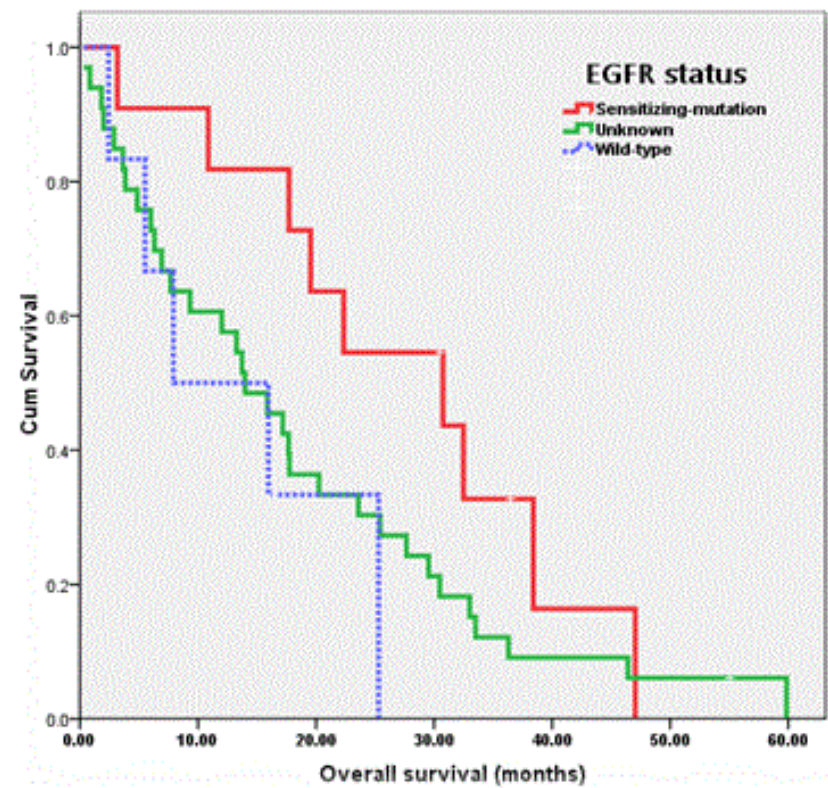

The median OS of patients received EGFR-TKIs as rechallenge or changing strategy was shown in Table 5.

Two and five years overall survival of all patients was 35.4 and 5.2 percent, respectively.

\section{Univariate analysis}

Univariate analysis results analyzed by Kaplan-Meier in the Table 5 showed that age group less than 70 year-old, nonsmoking, the way to access to an EGFR-TKI, ECOG status $0-1$, clinical benefit (partial response or stable disease) from an EGFR-TKI, receiving of EGFR-TKIs re-challenge and receiving chemotherapy were the favorable prognostic factors for the survival. While the other factors: sex, stage, tissue, adenocarcinoma, EGFR status, generic name of TKI, EGFRTKIs line of treatment, radiotherapy, pleural metastasis , lung metastasis, liver metastasis, bone metastasis and brain metastasis did not contribute as prognostic factors.

Figure 3. Overall survival according to EGFR status

Table 5. Univariate analysis of overall survival; ${ }^{*}$ TKI benefit -Yes includes partial response and stable disease to TKI therapy, No includes progression of disease and not available. \#TKI re-challenge or changing regimen. Abbreviation: 1L: First-line; 2 L: Second-line; CI: Confidence Interval; ECOG-PS: Eastern Cooperative Oncology Group-performance Status; EGFR: Epidermal Growth Factor Receptor; EGFR-TKI: Epidermal Growth Factor Receptor-Tyrosine Kinase Inhibitor; N: number; NA: Not Available; MN: Maintenance; mo: months; TKI: Tyrosine Kinase Inhibitor

\begin{tabular}{|c|c|c|c|c|c|c|}
\hline Factor & & $\mathrm{N}=50$ & Death $=46$ & $\begin{array}{l}\text { Median survival } \\
(\mathrm{mo})\end{array}$ & $95 \% \mathrm{Cl}$ of median survival & $p$-value \\
\hline \multicolumn{2}{|l|}{ All patient } & 50 & 46 & 17.18 & $12.96-21.40$ & \\
\hline \multirow[b]{2}{*}{ Sex } & Male & 27 & 26 & 13.99 & $5.35-22.63$ & \multirow[t]{2}{*}{0.255} \\
\hline & Female & 23 & 20 & 23.58 & $12.43-34.74$ & \\
\hline \multirow[b]{2}{*}{ Age } & $<70$ & 44 & 40 & 17.74 & $13.89-21.58$ & \multirow[t]{2}{*}{0.002} \\
\hline & $\geq 70$ & 6 & 6 & 6.3 & $1.81-10.80$ & \\
\hline \multirow[b]{2}{*}{ Smoking } & Never & 31 & 27 & 25.29 & $15.18-35.41$ & \multirow[t]{2}{*}{0.001} \\
\hline & Current/former & 19 & 19 & 7.91 & $4.50-11.32$ & \\
\hline \multirow[b]{2}{*}{ ECOG-PS } & $0-1$ & 27 & 23 & 27.66 & $18.82-36.50$ & \multirow[t]{2}{*}{$<0.001$} \\
\hline & $2-4 / N A$ & 23 & 23 & 6.3 & $3.06-9.54$ & \\
\hline \multirow[b]{3}{*}{ TKI access } & Reimbursement & 16 & 16 & 17.7 & $10.68-24.72$ & \multirow[t]{3}{*}{0.006} \\
\hline & Payment & 26 & 22 & 17.74 & $11.62-23.86$ & \\
\hline & Compassionate Use & 7 & 7 & 6.01 & $4.74-7.27$ & \\
\hline \multirow[b]{2}{*}{ Stage } & IIIB & 2 & 2 & 1.84 & -- & \multirow[t]{2}{*}{0.328} \\
\hline & IV & 48 & 44 & 17.18 & $13.05-21.31$ & \\
\hline \multirow[b]{2}{*}{ Tissue } & Cytology & 7 & 6 & 17.18 & $0.00-37.33$ & \multirow[t]{2}{*}{0.658} \\
\hline & Pathology & 43 & 40 & 17.67 & $12.98-22.36$ & \\
\hline Adenocarcinoma & Yes & 45 & 41 & 17.7 & $13.16-22.25$ & 0.974 \\
\hline
\end{tabular}


Citation: Sukauichai S,Tovanabutra C, Wanglikitkul S, et al. Survival of patients with advanced NSCLC treated with first-generation EGFRTKIs at a cancer hospital in Thailand, 2011-2016. J Med Oncl Ther 2018;3(2):23-31.

\begin{tabular}{|c|c|c|c|c|c|c|}
\hline & No & 5 & 5 & 13.27 & $0.00-35.56$ & \\
\hline \multirow[b]{3}{*}{ EGFR mutation status } & Sensitizing & 11 & 9 & 30.75 & $13.76-47.74$ & \multirow[t]{3}{*}{0.086} \\
\hline & Wild-type & 6 & 5 & 7.91 & $0.00-20.45$ & \\
\hline & Unknown & 33 & 32 & 13.99 & $8.19-19.80$ & \\
\hline \multirow[b]{2}{*}{ EGFR-TKI } & Gefitinib & 35 & 31 & 17.74 & $9.49-25.99$ & \multirow[t]{2}{*}{0.503} \\
\hline & Erlotinib & 15 & 15 & 16.62 & $9.20-24.04$ & \\
\hline \multirow[b]{2}{*}{ TKI treatment } & $1 \mathrm{~L} / \mathrm{MN}$ & 18 & 16 & 15.86 & $10.26-21.46$ & \multirow[t]{2}{*}{0.187} \\
\hline & $2 \mathrm{~L}$ or more & 32 & 30 & 17.7 & $9.05-26.36$ & \\
\hline \multirow[b]{2}{*}{ TKI Benefit* } & Yes & 30 & 26 & 22.34 & $9.52-35.15$ & \multirow[t]{2}{*}{0.001} \\
\hline & No/NA & 20 & 20 & 7.68 & $5.52-9.84$ & \\
\hline \multirow[b]{2}{*}{ TKI re-challenge\# } & Yes & 9 & 7 & 33.51 & $23.81-43.21$ & \multirow[t]{2}{*}{0.012} \\
\hline & No & 41 & 39 & 13.73 & $7.46-19.99$ & \\
\hline \multirow[b]{2}{*}{ Chemotherapy } & Yes & 43 & 39 & 19.54 & $13.74-25.35$ & \multirow[t]{2}{*}{$<0.001$} \\
\hline & No & 7 & 7 & 3.64 & $2.46-4.82$ & \\
\hline \multirow[b]{2}{*}{ Radiotherapy } & Yes & 27 & 26 & 17.67 & $14.73-20.61$ & \multirow[t]{2}{*}{0.814} \\
\hline & No & 23 & 20 & 15.96 & $0.00-34.06$ & \\
\hline \multirow[b]{2}{*}{ Pleural metastasis } & Yes & 20 & 18 & 20.23 & $3.31-37.15$ & \multirow[t]{2}{*}{0.337} \\
\hline & No & 30 & 28 & 15.86 & $11.32-20.41$ & \\
\hline \multirow[b]{2}{*}{ Lung metastasis } & Yes & 32 & 30 & 19.54 & $11.07-27.41$ & \multirow[t]{2}{*}{0.317} \\
\hline & No & 18 & 16 & 10.87 & $5.27-16.47$ & \\
\hline \multirow[b]{2}{*}{ Liver metastasis } & Yes & 13 & 12 & 17.74 & $6.74-28.73$ & \multirow[t]{2}{*}{0.748} \\
\hline & No & 37 & 34 & 17.18 & $12.88-21.43$ & \\
\hline \multirow[b]{2}{*}{ Bone metastasis } & Yes & 25 & 23 & 17.7 & $11.97-23.44$ & \multirow[t]{2}{*}{0.949} \\
\hline & No & 25 & 23 & 15.96 & $4.86-27.06$ & \\
\hline \multirow[b]{2}{*}{ Brain metastasis } & Yes & 21 & 21 & 17.74 & $13.90-21.57$ & \multirow[t]{2}{*}{0.99} \\
\hline & No & 29 & 25 & 13.73 & $6.80-20.16$ & \\
\hline
\end{tabular}

\section{Multivariate analysis}

The significant prognostic factors $(\mathrm{p}$ value $<0.05)$ in univariate analysis, including age, smoking, TKI access, ECOG performance status and TKI benefit were further analyzed in Cox-regression model; with the exception for chemotherapy and receiving of EGFR-TKIs re-challenge. As the decision to perform chemotherapy depended on an ECOG performance status and whether the patients received of TKI re-challenge relied on previous TKI benefit and TKI access, for example patients with compassionate use could not easily receive rechallenge TKI. Multivariate analysis data were shown in Table 6.

Cox-regression indicated that current or former smoking $(p=0.006)$, ECOG performance status 2-4 and not available $(\mathrm{p}<0.001)$, receiving EGFR-TKIs by payment $(\mathrm{p}=0.040)$ or compassionate use $(\mathrm{p}<0.001)$ were the poor prognostic factors for the OS.

\section{Discussion}

The median OS of patients with sensitizing EGFR mutation in this study was comparable (30.4 versus $19.3-37.3$ months) to those of other pivotal studies [3-9, 14-16] and larger real-life settings [17-22]. All in all, most of EGFR mutation patients in the present study harbouring exon 19 mutation, which naturally had a longer survival compared with those of exon $21[29,30]$. The median OS of patients with wild-type tumor was less than those of some other studies [3,4] (7.9 versus 18.4 months), due to higher number of patients with poor performance status included in the study. In addition, a small number of patients in the present study may limit the power to demonstrate the difference in OS of patients harbouring EGFR sensitizing mutation and of those with EGFR unknown (30.4 versus 13.9 months). However, OS of patients with EGFR wild-type (7.9 
months) was much shorter than those of the EGFR sensitizing mutation group.

Table 6. Multivariate analysis of overall survival; *TKI benefit -Yes includes partial response and stable disease to TKI therapy. No includes progression of disease and not available. Abbreviation: ECOG-PS: Eastern Cooperative Oncology Group-performance Status; HR: Hazard Ratio; N: number; NA: Not Available; TKI: Tyrosine Kinase Inhibitor.

\begin{tabular}{|c|c|c|c|c|}
\hline Factor & & $\mathrm{HR}$ & $95 \% \mathrm{Cl}$ & p-value \\
\hline \multirow{2}{*}{ Age } & $<70$ & 1 & \multirow[b]{2}{*}{$1.00-11.04$} & \multirow[b]{2}{*}{0.05} \\
\hline & $\geq 70$ & 3.32 & & \\
\hline \multirow{2}{*}{ Smoking } & Never & 1 & \multirow[b]{2}{*}{$1.42-8.75$} & \multirow[b]{2}{*}{0.006} \\
\hline & Current/former & 3.53 & & \\
\hline \multirow{2}{*}{ ECOG-PS } & $0-1$ & 1 & \multirow[b]{2}{*}{$2.58-12.22$} & \multirow[b]{2}{*}{$<0.001$} \\
\hline & $2-4 / N A$ & 5.62 & & \\
\hline \multirow{3}{*}{ TKI access } & Reimbursement & 1 & \multirow[b]{2}{*}{$1.03-4.60$} & \multirow[b]{2}{*}{0.04} \\
\hline & Payment & 2.18 & & \\
\hline & $\begin{array}{l}\text { Compassionate } \\
\text { Use }\end{array}$ & 19.86 & $4.77-82.74$ & $<0.001$ \\
\hline \multirow{2}{*}{ TKI benefit* } & Yes & 1 & \multirow[b]{2}{*}{$0.40-2.26$} & \multirow[b]{2}{*}{0.91} \\
\hline & No/NA & 0.91 & & \\
\hline
\end{tabular}

Considerably, two-third of patients in this study received an EGFR-TKI when their EGFR status was unknown. There were many reasons to explain this phenomenon at that time. First, it was controversial and some clinical evidence suggested using an EGFR-TKI as second-line treatment or more in unselected patients [31-34]. Secondly, although first-line therapy with an EGFR-TKI should be limited to patients harbouring sensitive EGFR mutation $[1,2]$, thanks to high prevalence of an EGFR sensitive mutation with lung adenocarcinoma in Thais [35], and sometimes in situations had nothing to lose such as a poor performance status or a critically ill patient unsuitable for a chemotherapy, an oncologist and a patient decided to try treating with an EGFR-TKI and closed follow up the clinical outcome in a few weeks later. Thirdly, the reimbursement system accepted the use of an EGFR-TKI as second-line or more regardless of EGFR status at that period of time. Moreover, the number of patient (13\%) in this study was diagnosed by tissue cytology with neither cell-block nor liquidbased technique, which was the barrier to perform molecular testing. Lastly, $\mathrm{CCH}$ has no in-house molecular testing laboratory and is a regional referral center. Therefore, when an oncologist requested for such the testing, a patient needed to get a tissue sample and brought it to $\mathrm{CCH}$ before being sent to another pathology center in Bangkok, which was a time consuming process. During waiting for EGFR mutation testing result, on the basis of clinical selection (such as non-smoker, adenocarcinoma, female), an oncologist might decide to try treating a patient and made a decision again depending on a clinical response or a testing result.
Fortunately, many recent clinical studies [36-38] including meta-analysis [39] indicated that the patients with wild-type gained benefit clinically from chemotherapy rather than an EGFR-TKI. Besides, according to many recent retrospective studies, it was acceptable to perform empiric therapy with an EGFR-TKI based on clinical judgment on poor performance status patients, but finally it would be more accurate and more reasonable to confirm an EGFR status in these patients [40,41]. In addition, the current reimbursement system in Thailand changes the criteria for applying an EGFR-TKI by permitting patients only with an EGFR sensitive mutation to use it as (but not limited to) a first-line therapy. Moreover, a liquid biopsy has become more acceptable and available in Thailand since the end of 2016. Lastly and most importantly, the price of an EGFR-TKI has been decreased from 2,200 Thai-bath (about 71 US dollar)/tablet/day to $600-720$ Thai-bath/tablet/day since February 2018.

For these reasons, the authors believe that lung cancer treatment with EGFR-TKIs in Thailand will be improved not only to the right person at the right time, but also to a number of EGFR mutated lung cancer patients. This real-life study emphasizes the crucial role of an EGFR mutation testing before initial treatment with an EGFR-TKI regardless of a line of therapy, prevalence of EGFR mutation in population, or even ECOG performance status of patients.

Median TAT in this study was 5 days consistent with a recommendation of a standard molecular testing guideline [42]. Besides TAT, processing time should be added and considered as waiting time in real world practice especially in a hospital not having in-house molecular testing. As a result, median waiting time in this study was approximately 14 days which was quite long.

As for prognostic factors, like other studies; smoking status $[18,21,31,43]$ and ECOG performance status $[18,21,43]$ had a significant impact on OS in patients receiving an EGFR-TKI. Reported by Okamoto [18] as a significant prognostic factor, age in this study showed a trend to be, but not because of limitation by a small number of patients in the study. Interestingly, this study indicated that access to an EGFR-TKI had an important role in OS; patients received a TKI by a reimbursement was a good prognostic factor compared with those received by an out-of pocket or a compassionate use.

\section{Conclusion}

The OS of the patients harbouring EGFR sensitizing-mutation in the present study was comparable to those of landmark phase III trials and those of other real-life reports. In real practice at that time in Thailand, most of the patients still have not been proved their EGFR statuses before starting an EGFRTKI and often received it as a late line therapy.

\section{Conflict of Interest}

The authors declared no conflict of interest. 
Citation: Sukauichai S,Tovanabutra C, Wanglikitkul S, et al. Survival of patients with advanced NSCLC treated with first-generation EGFRTKIs at a cancer hospital in Thailand, 2011-2016. J Med Oncl Ther 2018;3(2):23-31.

\section{Ethical Approval}

This article does not contain any studies with human participants performed by any of the authors and was approved by Ethics Committee of $\mathrm{CCH}$ and its later amendments or comparable ethical standards.

\section{Acknowledgements}

The authors feel grateful and thank to Associate professor Dusit Sujirarat, who kindly provided his suggestion on statistical analysis in this research.

\section{References}

1. GLOBOCAN 2012: Estimated Cancer Incidence, Mortality and Prevalence Worldwide in 2012. International Agency for Research on Cancer. 2012.

2. Schiller JH, Harrington D, Belani CP, et al. Comparision of four chemotherapy regimens for advanced non-small cell lung cancer. N Engl J Med. 2002; 346:92-8.

3. Mok TS, Wu YL, Thongprasert S, et al. Gefitinib or carboplatin-paclitaxel in pulmonary adenocarcinoma. $\mathrm{N}$ Engl J Med. 2009;361:947-57.

4. Han JY, Park K, Kim SW, et al. First-SIGNAL: First-line single-agent iressa versus gemcitabine and cisplatin trial in never-smokers with adenocarcinoma of the Lung. J Clin Oncol. 2012;30:1122-8.

5. Maemondo M, Inoue A, Kobayashi K, et al. Gefitinib or chemotherapy for non-small-cell lung cancer with mutated EGFR. N Engl J Med. 2010; 362:2380-8.

6. Mitsudomi T, Morita S, Yatabe Y, et al. Gefitinib versus cisplatin plus docetaxel in patients with non-small-cell lung cancer harbouring mutations of the epidermal growth factor receptor (WJTOG3405): An open label, randomized phase 3 trial. Lancet Oncol. 2010;11:121-8.

7. Zhou $\mathrm{C}, \mathrm{Wu} \mathrm{YL}$, Chen $\mathrm{G}$, et al. Erlotinib versus chemotherapy as first-line treatment for patients with advanced EGFR mutation-positive non-small cell lung cancer (OPTIMAL, CTONG-0802): A multicentre, openlabel, randomised, phase 3 study. Lancet Oncol. 2011;12:735-42.

8. Rosell R, Carcereny E, Gervais R, et al. Erlotinib versus standard chemotherapy as first-line treatment for European patients with advanced EGFR mutation-positive nonsmall-cell lung cancer (EURTAC): A multicentre, openlabel, randomized phase 3 trial. Lancet Oncol. 2012;13:239-46.

9. $\mathrm{Wu}$ YL, Zhou C, Liam C, et al. First-line erlotinib versus gemcitabine/cisplatin in patients with advanced EGFR mutation-positive non-small-cell lung cancer: Analyses from the phase III, randomized, open-label, ENSURE study. Ann Oncol. 2015;26: 1883-9.

10. Reck M, Rodriguez-Abreu D, Robinson AG, et al. Pembrolizumab versus chemotherapy for PD-L1-positive non-small-cell lung cancer. $\mathrm{N}$ Engl J Med. 2016; 375:1823-33.

11. Moyo-Horno I, Viteri S, Karachaliou N, et al. Combination of immunotherapy with targeted therapies in advanced non-small cell lung cancer (NSCLC). Ther Adv Med Oncol. 2018;10:1-12.

12. NCCN National Practice Guideline in Oncology. NonSmall Cell Lung Cancer Version5-2018. National Comprehensive Cancer Network. 2018

13. Novello S, Barlesi F, Califano R, et al. Metastatic nonsmall-cell lung cancer: ESMO Clinical practice guidelines for diagnosis, treatment and follow-up. Ann Oncol. 2016;27:1-27.

14. Fukuoka M, Wu YL, Thongprasert S, et al. Biomarker analyses and final overall survival results from a phase III, randomized, open-label, first-line study of gefitinib versus carboplatin/paclitaxel in clinically selected patients with advanced non-small-cell lung cancer in Asia (IPASS). J Clin Oncol. 2011;29:2866-74.

15. Yoshioka H, Mitsudomi T, Morita S, et al. Final overall survival results of WJTOG 3405, a randomized phase 3 trial comparing gefitinib with cisplatin plus docetaxel as the first-line treatment for patients with non-small cell lung cancer harboring mutations of the epidermal growth factor receptor (EGFR). J Clin Oncol. 2014;32:8117.

16. Zhou C, Wu YL, Chen G, et al. Final overall survival results from a randomised, phase III study of erlotinib versus chemotherapy as first-line treatment of EGFR mutation-positive advanced non-small cell lung cancer (OPTIMAL, CTONG-0802). Ann Oncol. 2015;26:187783.

17. Lin JJ, Cardarella S, Lydon CA, et al. Five-year survival in EGFR-mutant metastatic lung adenocarcinoma treated with EGFR-TKIs. J Thorac Oncol. 2016; 11: 556-65.

18. Okamoto I, Morita S, Tashiro N, et al. Real world treatment and outcomes in EGFR mutation-positive nonsmall cell lung cancer: long-term follow-up of a large patient cohort. Lung Cancer. 2018;117:14-9.

19. Arriola E, Gómez RG, Diz P, et al. Clinical management and outcome of patients with advanced NSCLC carrying EGFR mutations in Spain. BMC cancer. 2018:106.

20. Cadranel J, Brambilla E, Morere JF, et al. Real life practice of gefitinib in patients with non-small-cell lung cancer depending on epidermal growth factor receptor mutation status: Results from the prospective EPIDAURE study . J Thorac Oncol. 2016;11:130-1.

21. Yao ZH, Liao WY, Ho CC, et al. Real-World data on prognostic factors for overall survival in EGFR mutationpositive advanced non-small cell lung cancer patients treated with first-line gefitinib. Oncologist. 2017; 22:1075-83.

22. Febriani A, Wulandari L, Wati FF, et al. The evaluation of lung cancer patients treated with EGFR-TKI gefitinib as first-line treatment: The Indonesian experience. Ann Oncol. 2016;27.

23. Prempree T, Wongpaksa C. EGFR mutation in lung cancer treated by gefitinib in Thailand. Lung Cancer. 2005;49:375.

24. Charoentum C, Thongprasert S, Chewaskulyong B, et al. Clinical predictor of response to gefitinib in Thai patients 
with non-small cell lung cancer. J Thorac Oncol. 2007;2:709.

25. Prempree T. Managing EGFR T790M mutation in advanced non-small cell lung cancer in Thailand. J Thorac Oncol. 2017;12:2137.

26. Reungwetwattana T, Laohavinij S, Lamlertthon W, et al. Efficacy \& tolerability of afatinib in NSCLC patients prior exposure to $1 \mathrm{st}$ generation EGFR-TKI: Thailand multicenter study . J Thorac Oncol 2017;12:2217.

27. Mirsadraee S, Oswal D, Alizadeh Y, et al. The 7th lung cancer TNM classification and staging system: Review of the changes and implications. World J Radiol. 2012; 4:128-34.

28. Eisenhauer EA, Therasse P, Bogaerts J, et al. New response evaluation criteria in solid tumours: Revised RECIST guideline (version 1.1). Eur J Cancer. 2009;45: 228-47.

29. Riely GJ, Pao W, Pham DK, et al. Clinical course of patients with non-small cell lung cancer and epidermal growth factor receptor exon19 and exon 21 mutations treated with gefitinib or erlotinib. Clin Cancer Res. 2006;12:839-44.

30. Jackman DM, Yeap BY, Sequist LV, et al. Exon 19 deletion mutations of epidermal growth factor receptor are associated with prolonged survival in non-small cell lung cancer patients treated with gefitinib or erlotinib. Clin Cancer Res. 2006;12: 3908-14.

31. Shepherd FA, Pereira JR, Ciuleanu T, et al. Erlotinib in previously treated non-small cell lung cancer. $\mathrm{N}$ Engl J Med. 2005;353:123-32.

32. Hirsh V, Mok T, Socinski MA, et al. Gefitinib versus docetaxel in previously treated non-small-cell lung cancer: A randomised phase III trial. The Lancet. 2008; 372:1809-18.

33. Sun JM, Lee KH, Kim SW, et al. Gefitinib versus pemetrexed as second-line treatment in patients with nonsmall cell lung cancer previously treated with platinumbased chemotherapy (KCSG-LU08-01). Cancer. 2012;118:6234-42.

34. Laurie SA, Goss GD. Role of epidermal growth factor receptor inhibitors in epidermal growth factor receptor wild-type non-small cell Lung Cancer. J Clin Oncol. 2013; 31:1061-9.

35. Sriuranpong V, Chantranuwat C, Huapai N, et al. High frequency of mutation of epidermal growth factor receptor in lung adenocarcinoma in Thailand. Cancer Lett. 2006; 239:292-7.
36. Garassino MC, Martelli O, Broggini M, et al. Erlotinib versus docetaxel as second-line treatment of patients with advanced non-small-cell lung cancer and wild-type EGFR tumours : A randomised controlled trial. Lancet Oncol. 2013;14:981-8.

37. Kawaguchi T, Ando M, Asami K, et al. Randomized phase III trial of erlotinib versus docetaxel as second- or thirdline therapy in patients with advanced non-small cell lung cancer: docetaxel and erlotinib lung cancer trial (DELTA). J Clin Oncol. 2014;32:1902-8.

38. Zhou Q, Cheng Y, Yang JJ, et al. Pemetrexed versus gefitinib as a second-line treatment in advanced nonsquamous non-small cell lung cancer patients harboring wild-type EGFR (CTONG0806): A multicenter randomized trial. Ann Oncol. 2014; 25: 2385-91.

39. Vale CL, Burdett S, Fisher DJ, et al. Should tyrosine kinase inhibitors be considered for advanced non-small cell lung cancer patients with wild type EGFR? Two systematic reviews and meta-analyses of randomized trials. Clin Lung Cancer. 2015;16:173-82.

40. Yang CY, Shih JY, Yu CJ. Treatment of non-small cell lung cancer patients in the intensive care units with epidermal growth factor receptor-tyrosine kinase inhibitors. Am J Respir Crit Care Med. 2012; 185.

41. Chen YF, Lin JW, Ho CC, et al. Outcomes of cancer therapy administered to treatment-naïve lung cancer patients in the intensive care unit. J Cancer. 2017;8: 1995-2003.

42. Lindeman NI, Cagle PT, Beasley MB, et al. Molecular testing guideline for selection of lung cancer patients for EGFR and Alk tyrosine kinase inhibitors: Guideline from the college of American pathologists, international association for the study of lung cancer, and association for molecular pathology. J Thorac Oncol. 2013;8: 823-59.

43. Zheng Z, Jin X, Lin B, et al. Efficacy of second-line tyrosine kinase inhibitors in the treatment of metastatic advanced non-small cell lung cancer harboring exon 19 and 21 EGFR mutations. J Cancer. 2017;8:597-605.

\section{*Correspondence to:}

Sitthi Sukauichai

Chemotherapy Unit

Chonburi Cancer Hospital

Chonburi, Thailand

E-mail: maxstmdcu@yahoo.com 